\title{
SANITASI PERALATAN DAN PENGGUNAAN PEWARNA MAKANAN SINTESIS PADA JAJANAN TRADISIONAL (CENIL DAN LUPIS) DI KELURAHAN ARJOSARI KOTA MALANG
}

\author{
Frida Dwi Anggraeni ${ }^{*}$, Enny Sumaryati \\ ${ }^{1,2}$ Fakultas Pertanian, Universitas Widyagama Malang \\ *Email Korespondensi : fridadwi@widyagama.ac.id
}

\begin{abstract}
ABSTRAK
Cenil dan lupis merupakan jajanan yang banyak dijual di pasar-pasar tradisional. Bahan baku utama untuk membuat cenil adalah tepung kanji, sedangkan bahan baku utama untuk lupis adalah beras ketan. Biasanya dibalut dengan parutan kelapa dan gula merah yang sudah dicairkan. Di Kelurahan Arjosari Kota Malang, terdapat penjual jajanan tradisional yang juga membuat sendiri makanan tersebut. Akan tetapi, masih terdapat kelemahan pada aspek produksi maupun dari aspek manajemennya. Diantaranya adalah penggunaan peralatan panci dandang yang terbuat dari aluminium dan sudah berkarat, asap dari tungku (pawon) dengan bahan bakar kayu yang menyebabkan pencemaran udara, ketidaktahuan mitra dalam menggunakan pewarna sintesis yang tepat untuk cenil, dan kurang dalam mempromosikan jajanan tradisional ini. Tujuan dari pengabdian ini adalah memperbaiki sanitasi peralatan yang digunakan untuk pembuatan cenil dan lupis, mengurangi pencemaran udara selama produksi, menentukan batas maksimum penggunaan pewarna makanan sintesis pada cenil yang sesuai dengan BPOM, serta meningkatkan aspek pemasarannya. Metode yang digunakan dalam pengabdian ini adalah pencarian referensi, sosialisasi dan pendampingan penggunaan pewarna makanan sintesis, desain alat untuk panci dengan bahan dasar stainless steel, penggantian tungku dengan kompor gas bertekanan tinggi, dan pembuatan banner. Hasilnya dapat memperbaiki higienitas peralatan yang digunakan karena terbuat dari stainless steel yang tidak mudah bereaksi dengan makanan, tidak adanya pencemaran udara karena tidak menimbulkan asap di sekitar tempat produksi, mengetahui batas maksimum penggunaan pewarna makanan yang aman untuk dikonsumsi berdasarkan BPOM yaitu 70 $\mathrm{mg} / \mathrm{kg}$, atau setara dengan 1 tetes untuk tiap $\mathrm{kg}$ bahan. Kemudian dari aspek manajemennya, dengan adanya banner tersebut dapat memperkenalkan produk jajanan tradisional untuk menarik minat masyarakat.
\end{abstract}

Kata kunci : pewarna sintesis, stainless steel, kompor gas bertekanan tinggi, banner

\section{ABSTRACT}

Cenil and lupis are food that are widely sold in traditional markets. The main raw material to make cenil is tapioca starch, while the main raw material for lupis is sticky rice. Usually wrapped with grated coconut and brown sugar that had been thawed. In Arjosari Village, Malang City, there is a traditional food seller who also makes their food. However, there were still weaknesses in production and management aspects. Among them was the use of equipment that made from aluminium and had been rusty, smoke from the stove (pawon) with wood fuel which causes air pollution, partners ignorance in using the right synthetic food colour for cenil, and less in promoting this traditional food. The purpose was to improve the sanitation of utensils that used for cenil and lupis manufacturing, reduce air pollution during production, determine the maximum limit the use of synthetic food colour in cenil that accordance with BPOM, and improve its marketing aspects. The methods were searching for references, socialising and assisting in the use of synthetic food colour, designing of utensil pans with stainless steel-based, replacement with high-pressure gas stoves, and making the banner. The result can improve the equipment hygiene because it was made of stainless steel which was not easy to react with food, the absence of air pollution because it did not causes smoke around the production site, know the maximum limit the use of food colour that is safe for consumption based on BPOM that is $70 \mathrm{mg} / \mathrm{kg}$, or it equivalent with 1 drop per $\mathrm{kg}$ of material. Then from the management aspect, with the banner can introduce traditional food to attract the interest of the society.

Keywords : synthetic food colour, stainless steel, high-pressure gas stove, banner 


\section{PENDAHULUAN}

Jajanan tradisional merupakan makanan yang sering kita temui di setiap daerah di Indonesia. Ciri khas jajanan tradisional adalah bahan sederhana dan mudah ditemukan di sekitar kita, tetapi tidak tahan lama. Meskipun telah banyak beredar makanan instan dan modern bahkan impor dari luar negeri, jajanan tradisional atau jajanan pasar masih tetap digemari karena beberapa alasan, antara lain harganya yang relatif terjangkau dengan rasa yang manis dan gurih, serta banyak beragam pilihan yang disediakan.

Jajanan tradisional sangat beragam jenisnya. Diantaranya adalah klepon, cenil, kue talam, nagasari, lupis, dan lain - lain. Bahan baku utama yang digunakan biasanya terbuat dari tepung beras ketan, tepung sagu/kanji, atau tepung beras. Ada yang dibalut dengan parutan kelapa dan gula merah yang sudah dicairkan. Untuk pewarnanya, biasanya menggunakan bahan pewarna alami pasta pandan atau bahan pewarna makanan yang aman untuk dikonsumsi.

Cenil merupakan salah satu jajanan favorit yang banyak dijual di pasar-pasar tradisional. Makanan ini terbuat dari tepung kanji, yang dibuat dalam bentuk lonjong, memiliki berbagai macam warna, salah satunya berwarna merah muda sampai merah cerah, rasanya manis dan kenyal. Dalam penyajiannya, cenil biasanya ditaburi parutan kelapa muda.

Bahan pewarna yang digunakan dalam pembuatan cenil ini adalah pewarna makanan sintesis. Warna merupakan daya tarik terbesar untuk menikmati makanan setelah aroma. Penambahan pewarna makanan ini dengan tujuan dapat memperbaiki penampilan cenil agar terkesan menarik bagi konsumen, menyeragamkan dan mempertajam warna makanan itu sendiri.

Bahan pewarna sintetis mempunyai keunggulan dari zat pewarna alami dalam hal pewarnanya dan stabilitasnya yang lebih baik. Karena keunggulan-keunggulan tersebut maka banyak produsen makanan beralih dari bahan pewarna alami ke bahan pewarna sintetis. Sekarang ini lebih dari 90 persen bahan pewarna yang digunakan dalam industri makanan adalah bahan pewarna sintetis (Enie, 1999 dalam Tatung, 2013).

Di Indonesia, peraturan mengenai penggunaan bahan pewarna yang diizinkan dan dilarang untuk pangan diatur melalui SK Menteri Kesehatan RI Nomor 722/Menkes/ Per/IX/88 mengenai Bahan Tambahan Pangan (BTP). Akan tetapi, seringkali terjadi penyalahgunaan pemakaian untuk tekstil dan kulit dipakai untuk mewarnai bahan pangan, yang jelas berbahaya bagi kesehatan karena adanya residu logam berat pada bahan pewarna tersebut. Timbulnya penyalahgunaan ini disebabkan oleh ketidaktahuan masyarakat mengenai bahan pewarna untuk pangan, dan harga bahan pewarna untuk industri jauh lebih murah dibandingkan dengan harga bahan pewarna untuk pangan, juga warna dari bahan pewarna tekstil atau kulit lebih menarik (Cahyadi, 2006).

Sedangkan lupis merupakan makanan khas yang terbuat dari beras ketan. Proses pembuatannya cukup lama karena proses perendaman beras ketan kurang lebih 2 jam dan pengukusan membutuhkan waktu bisa berjam - jam untuk memperoleh tekstur lupis yang lembut dan pulen. Lupis ini tidak menggunakan bahan tambahan pangan, dan dalam penyajiannya, lupis biasanya ditaburi dengan parutan kelapa dan dilumuri dengan gula merah.

Dalam proses pembuatan cenil dan lupis ini, juga perlu diperhatikan mengenai sanitasi atau higiene dalam pengolahannya agar makanan tersebut tidak terkontaminasi oleh mikroorganisme penyebab penyakit, bahan kimia maupun bahan asing lainnya yang dapat membahayakan keamanan pangan. Salah satunya adalah pemilihan peralatan yang digunakan dalam pengolahan makanan tersebut harus mempertimbangkan bahan yang digunakan dan kemudahan pembersihannya (Rauf, 2013).

Di Kelurahan Arjosari Kota Malang, terdapat penjual jajanan tradisional yaitu cenil, klepon, lupis, dan ongol - ongol sagu yang juga membuat sendiri makanan tersebut dan kemudian menjualnya di pasar tradisional setiap pagi. Usaha ini sudah berlangsung selama 
19 tahun, yakni sejak tahun 2000. Walaupun usaha tersebut sudah berlangsung lama, masih terdapat beberapa kelemahan, baik dari aspek produksi maupun dari aspek manajemennya. Permasalahan yang saat ini dialami oleh penjual jajanan cenil dan lupis tersebut adalah :

1. Sanitasi peralatan kurang baik karena panci dandang yang digunakan untuk merebus dan mengukus terbuat dari bahan yang mudah bereaksi dengan bahan pangan yaitu aluminium. Panci dandang yang terbuat dari aluminium ini tidak kuat karena selama pemanasan aluminium mudah mengalami elektrolisis, sehingga tidak direkomendasikan digunakan untuk memasak. Selain itu juga panci dandang sudah berkarat serta banyak tambalannya.

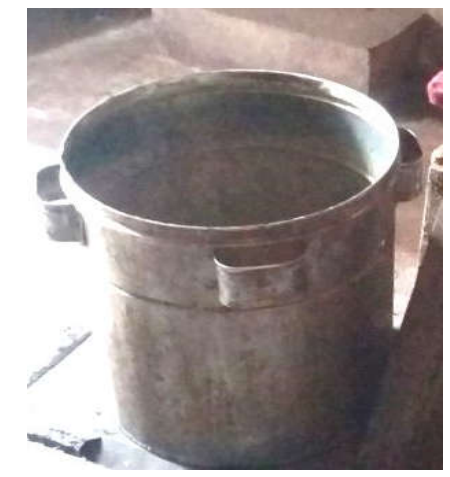

Gambar 1. Penggunaan panci dandang yang berkarat

2. Proses pengukusan beras ketan yang masih mengggunakan tungku (pawon) dengan api dari kayu bakar menyebabkan proses pengukusan berjalan sangat lama yaitu sekitar $6-$ 7 jam dan bau asap yang sangat terasa dan membuat sesak di sekitar ruangan walaupun ada ventilasi udara diatasnya. Hal ini menyebabkan sanitasi lingkungan di sekitar tempat proses produksi menjadi kurang baik.

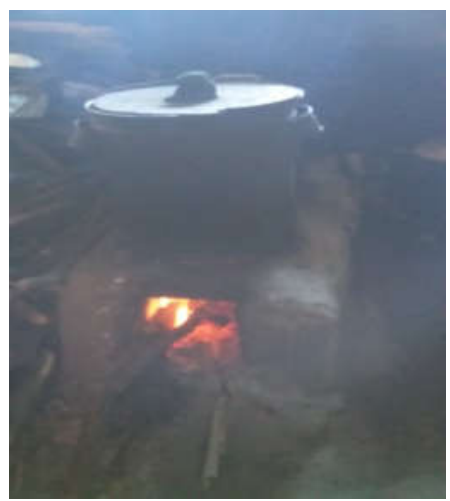

Gambar 2. Pengukusan diatas tungku (pawon)

3. Kurangnya pengetahuan tentang penggunaan pewarna makanan sintesis. Mengenai dosis penggunaan yang dianjurkan oleh Kemenkes serta efek yang ditimbulkan oleh tubuh apabila penggunaanya berlebih dan dalam jangka waktu lama.

4. Belum adanya banner untuk memperkenalkan jajanan tradi sionalnya sebagai media promosi kepada masyarakat.

Adapun tujuan dari Tim Ipteks bagi Masyarakat (IbM) dari Fakultas Pertanian Universitas Widyagama Malang ini adalah untuk memperbaiki kelemahan dalam proses pembuatan cenil dan lupis dari segi higiene peralatan, sanitasi lingkungan, pelatihan penggunaan pewarna makanan sintesis yang tepat, dan aspek pemasarannya. 


\section{METODE}

\section{Solusi Dan Target}

Pembuatan cenil ini dilakukan setiap hari, sekitar pukul 13.00 - 17.00 WIB dengan kapasitas produksi $3 \mathrm{~kg}$. Sedangkan untuk pembuatan lupis dilakukan dua hari sekali sekitar pukul $13.00-21.00$ WIB dengan kapasitas produksi $9 \mathrm{~kg}$. Adapun proses pembuatan cenil dan lupis ini adalah :

1. Cenil

Cenil ini dibuat dari bahan dasar tepung kanji yang dicampur dengan garam, gula pasir dan air matang secukupnya sampai membentuk suatu adonan dan mudah dibentuk. Kemudian adonan diberi pewarna makanan sintesis merah. Pewarna makanan ini bertujuan untuk memberikan penampakan yang menarik pada kue cenil. Setelah itu, adonan dicetak dengan cara dipilin - pilin dan dibentuk lonjong. Pilinan adonan ini dimasukkan kedalam air mendidih dan setelah mengapung, diangkat dan dipotong. Lama perebusan sekitar 2 jam. Kemudian parutan kelapa yang telah dikukus dan gula pasir tidak langsung dicampurkan, akan tetapi dicampurkan pada saat penjualan.

2. Lupis

Bahan dasar utama untuk membuat lupis adalah beras ketan. Beras ketan ini dicuci bersih dan direndam kurang lebih selama 2 jam dan setiap 15 menit air rendaman diganti. Selanjutnya beras ketan tersebut dibungkus dengan daun pisang, kemudian dikukus dengan menggunakan panci dandang yang berkapasitas 10 liter diatas kompor tungku yang menyala dengan bahan bakar kayu bakar sampai matang. Proses pengukusan dengan tungku ini memakan waktu yang cukup lama yaitu sekitar 6-7 jam. Kemudian untuk juruhnya dibuat dari gula merah yang ditambah sedikit air kemudian dipanaskan, sehingga terbentuk cairan kental. Sedangkan untuk kelapa parutnya juga agar tidak mudah berbau, dikukus dengan ditambah sedikit garam terlebih dahulu.

Berdasarkan analisis situasi yang telah diuraikan, maka rencana kegiatan pengabdian yang akan dilakukan adalah:

1. Mendesain alat panci dandang yang terbuat dari bahan yang aman digunakan dalam pengolahan yaitu yang terbuat dari baja tahan karat (stainless steel).

2. Mengganti tungku yang digunakan dengan kompor gas bertekanan tinggi sehingga waktu untuk mengukus jadi lebih cepat karena api yang besar dan panas lebih merata, serta tidak mengganggu sanitasi lingkungan sekitar karena tidak ada pencemaran asap yang ditimbulkan.

3. Melakukan pelatihan penggunaan BTP pewarna sintesis yang sesuai dengan standar kesehatan, serta memberi pengetahuan tentang zat pewarna sintesis yang aman dan yang dilarang penggunaannya di Indonesia menurut Peraturan Kemenkes.

4. Membuat banner untuk memperkenalkan produk jajanan tradisional yang dijual.

\section{Pelaksanaan}

Tim IbM telah melakukan penelusuran untuk mencari referensi mengenai BTP pewarna sintesis yang aman ditambahkan ke dalam makanan dan pewarna makanan sintesis yang dilarang, yang diatur menurut Peraturan Menteri Kesehatan RI no. 722/Menkes/Per/IX/1988 tentang zat warna yang dinyatakan berbahaya dan dilarang di Indonesia. Setelah itu tim juga melakukan sosialisasi dan pendampingan terhadap mitra mengenai pewarna makanan yang aman untuk dikonsumsi, batas maksimum yang diperbolehkan penggunaannya pada kue cenil sesuai dengan Peraturan BPOM, serta dampak yang ditimbulkan apabila penggunaan pewarna makanan ini melebihi dosis yang ditentukan. 

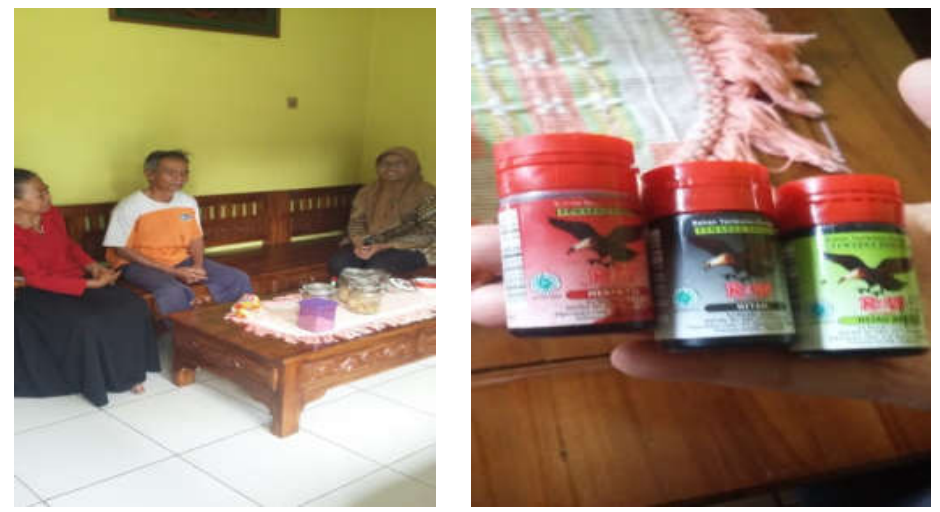

Gambar 3. Pendampingan penggunaan pewarna makanan sintesis

Kemudian untuk keperluan usaha mitra, tim juga telah mendesain dan membuat panci dandang besar dengan ukuran diameter $50 \mathrm{~cm}$ dan tinggi $60 \mathrm{~cm}$ yang terbuat dari baja tahan karat (stainless steel) dan juga mengganti tungku (pawon) yang digunakan untuk mengukus beras ketan dengan kompor jos/kompor gas bertekanan tinggi.

Dari segi manajemen usaha, untuk meningkatkan pemasaran dalam penjualan cenil dan lupis tersebut, tim IbM telah mendesain dan membuat banner sehingga dapat menarik minat pembeli jajanan tradisional ini dan mempromosikan produk yang dijual.

\section{HASIL DAN PEMBAHASAN}

\section{Aspek Produksi}

\section{Panci dandang dengan bahan dari baja tahan karat (stainless steel).}
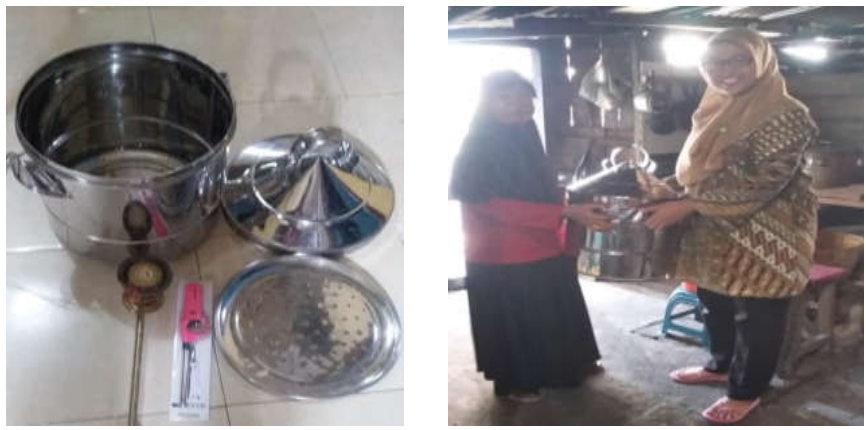

Gambar 4. Panci dandang hasil IbM

Panci ini berukuran besar dengan diameter $50 \mathrm{~cm}$ dan tinggi $60 \mathrm{~cm}$. Panci ini bisa untuk mengukus beras ketan hingga kapasitas $10 \mathrm{~kg}$. Sementara saringannya juga terbuat dari stainless steel (Gambar 4).

Prinsip higiene dan sanitasi makanan adalah pengendalian terhadap 4 faktor penyehatan makanan, yaitu tempat/bangunan, peralatan, orang dan bahan makanan. Penyehatan makanan adalah upaya untuk mengendalikan faktor tempat, peralatan, orang, dan makanan yang bisa menimbulkan gangguan kesehatan atau keracunan makanan. Peralatan makanan harus diperhatikan tingkat sanitasi, bahan peralatan, cara penyimpanan dan cara pencucian, karena peralatan makanan dapat menyebabkan kontaminasi silang penyebab food borne desease (Yulia, 2016).

Dengan panci dandang yang seluruhnya terbuat dari stainless steel ini, tidak mudah bereaksi dengan bahan pangan, sehingga aman digunakan selama proses perebusan maupun 
pengukusan. Selain itu, alat ini juga mudah untuk dibersihkan karena mempunyai tekstur yang rata, licin dan tidak berpori.

Pemilihan peralatan yang digunakan untuk membuat cenil maupun lupis ini harus mempertimbangkan bahan yang digunakan dan kemudahan untuk pembersihannya. Bahan yang digunakan untuk peralatan pengolahan pangan merupakan bahan yang tidak bereaksi dengan bahan pangan. Pertimbangan kemudahan pembersihan peralatan juga tergantung pada konstruksi alat tersebut (Rauf, R., 2013).

\section{Kompor gas bertekanan tinggi}

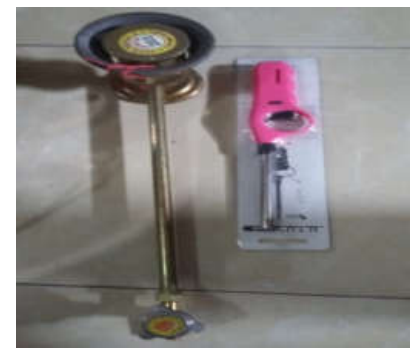

Gambar 5. Kompor gas bertekanan tinggi

Kompor gas bertekanan tinggi ini memiliki tekanan gas yang lebih tinggi dan ratarata diatas $1 / 2$ psi (per square inch) (Gambar 5). Adanya tekanan gas yang besar menjadikan pembakaran juga lebih cepat dan panas lebih merata sehingga pengukusan beras ketan tidak membutuhkan waktu yang sangat lama. Selain itu bagi mitra tidak menyebabkan pencemaran udara di sekitar lingkungan proses produksi karena tidak ada bau asap yang membuat sesak. Hal ini menyebabkan sanitasi lingkungannya menjadi baik.

\section{Sosialisasi dan pendampingan penggunaan pewarna makanan sintesis}

Pewarna sintesis atau buatan yang dipergunakan untuk makanan ini diperoleh melalui sintesis kimia buatan yang mengandalkan bahan - bahan kimia, atau dari bahan yang mengandung pewarna alami melalui ekstraksi secara kimiawi. Beberapa contoh pewarna buatan/sintesis yakni : tartrazin, sunset yellow (untuk warna kuning), allura, eritrosin, hijau FCF, dan beberapa pewarna buatan lainnya. Namun, ada juga pewarna makanan buatan yang tidak aman dan tidak layak untuk dikonsumsi. Seperti Rhodamin B dan metanil yellow yang sebenarnya merupakan pewarna tekstil yang dilarang penggunaannya dalam produk produk pangan (Direktorat Registrasi Pangan Olahan BPOM RI, 2018).

Tim telah melakukan sosialisasi dan pendampingan tentang penggunaan bahan pewarna makanan yang aman untuk dikonsumsi dan dosis pemakaian dalam pembuatan cenil. Mitra menggunakan pewarna makanan sintesis dengan merk "Rajawali" yang warna merah ini dari jenis pewarna Karmoisin $\mathrm{Cl} 14720$ dan warna hijau dari jenis pewarna hijau FCF Cl. no. 42053. Menurut Peraturan BPOM RI (2013), batas maksimum penggunaan pewarna makanan sintesis jenis karmiosin maupun hijau FCF untuk kue beras seperti cenil ini adalah $70 \mathrm{mg} / \mathrm{kg}$ atau setara dengan 1 tetes untuk tiap $\mathrm{kg}$ bahan.

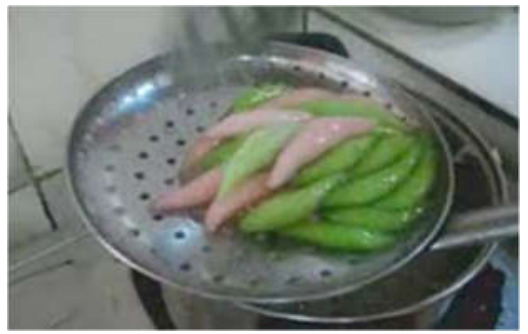

Gambar 6. Dosis yang tepat untuk penggunaan pewarna makanan sintesis 
Karmoisin merupakan pewarna makanan sintetik yang memberikan warna merah segar pada makanan dan minuman. Karmoisin tidak boleh dikonsumsi secara berlebihan, karena dapat menyebabkan alergi pada kulit dan mengaktifkan sel-sel kanker dalam tubuh. Sedangkan hijau FCF merupakan pewarna sintetis hijau yang sering digunakan pada minuman, serbuk instan, permen, puding, es krim dan produk-produk susu. Penggunaan pewarna ini jika berlebihan dapat menyebabkan reaksi alergi. Dalam label kemasan makanan pewarna ini berkode C.I. 42053, E143 atau FD \& C Green No. 3. Kedua pewarna sintesis ini memiliki batasan penggunaan yang tidak menimbulkan bahaya jika dikonsumsi manusia yaitu $50-300 \mathrm{mg}$ batas PERMENKER RI per $\mathrm{kg}$ makanan, dan $0-4 \mathrm{mg}$ batas ADI per $\mathrm{kg}$ berat badan (Karunia, 2013).

Cenil yang menggunakan pewarna sintesis Karmoisin ini memiliki ciri fisik warna merah muda terang, tidak berpendar, warna homogen dan rasanya alami. Sedangkan, apabila makanan yang mengandung zat pewarna Rhodamin $B$ yang tidak diperbolehkan untuk campuran makanan menurut Permenkes No. 722/MenKes/Per/1988, memiliki ciri-ciri fisik yaitu warna merah mencolok, cenderung berpendar, warna tidak pudar akibat pemanasan (digoreng maupun direbus), baunya tidak alami sesuai makanannya dan terdapat bintikbintik warna karena tidak homogen (Ristianingrum, dkk., 2018).

\section{Aspek Manajemen}

Pembuatan banner untuk meningkatkan pemasaran

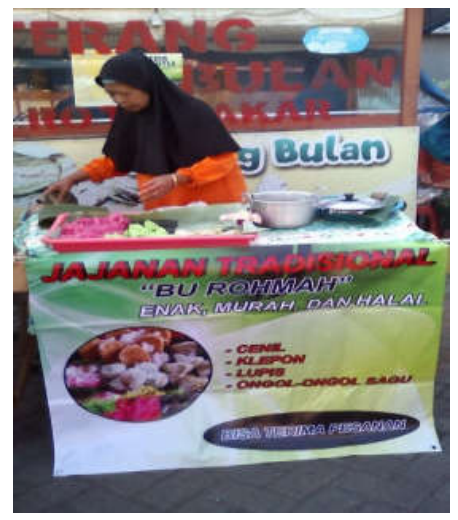

Gambar 7. Banner jajanan tradisional

Banner yang telah dibuat ini berukuran standar panjang $100 \mathrm{~cm}$ dan lebar $85 \mathrm{~cm}$ yang berisi informasi mengenai produk jajanan tradisional yang dijual mitra dan dipasang di depan meja tempat penjualan. Hal ini sangat penting karena dengan pemasangan banner ini dapat mempromosikan produk jajanan tradisional yang dijual mitra diantaranya ada cenil dan lupis, sehingga menarik perhatian lebih banyak masyarakat yang melihatnya sehingga pemasarannya juga akan meningkat.

\section{DAMPAK DAN MANFAAT}

Pendampingan dan pemberian alat yang telah dilakukan ini diharapkan dapat mendukung usaha dari ibu Rohmah agar mampu meningkatkan sanitasi proses produksi dan peralatan yang digunakan untuk pengolahan cenil dan lupis serta meningkatkan pengetahuan tentang penggunaan pewarna sintesis yang aman untuk dikonsumsi sehingga dapat meningkatkan kualitas dan produktivitasnya.

Penggunaan alat panci dandang yang berbahan stainless steel ini tidak mudah bereaksi dengan bahan pangan, sehingga aman digunakan selama proses perebusan maupun pengukusan. Selain itu, alat ini juga mudah untuk dibersihkan karena mempunyai tekstur yang rata, licin dan tidak berpori. 
Sedangkan penggunaan pewarna makanan sintesis ini sesuai dengan batas maksimum dosis yang telah ditetapkan. Karena apabila penggunaanya dalam jumlah yang banyak dan terus menerus, maka akan menimbulkan berbagai penyakit mulai dari penyakit ringan maupun penyakit yang dapat menyebabkan kematian (Helmati dalam Julaeha, 2016). Sehingga dengan pendampingan ini diharapkan dapat meningkatkan keamanan pangan dari jajanan cenil yang diproduksi.

\section{KESIMPULAN}

1. Perbaikan peralatan yang dilakukan adalah dengan mengganti panci dandang yang tadinya berbahan dasar aluminium dengan yang berbahan dasar stainless steel sehingga tidak mudah bereaksi dengan makanan yang ada didalamnya selama proses perebusan / pengukusan.

2. Batas maksimum penggunaan BTM pewarna sintetis warna merah jenis Karmoisin $\mathrm{Cl}$ no. 1470 dan warna hijau Tartrazine $\mathrm{Cl}$ no. 19140 dalam pembuatan cenil ini yaitu 70 $\mathrm{mg} / \mathrm{kg}$ adonan bahan atau setara dengan 1 tetes tiap $\mathrm{kg}$ adonan.

3. Pembuatan banner untuk meningkatkan pemasaran jajanan tradisional ini.

\section{UCAPAN TERIMA KASIH}

Kami sangat berterimakasih kepada Lembaga Penelitian dan Pengabdian kepada Masyarakat Universitas Widyagama Malang yang telah memberi bantuan biaya dalam Program Pengabdian Masyarakat (PROPENMAS) Tahun 2019/2020, Ibu Rohmah selaku pemilik usaha jajanan tradisional, serta seluruh pihak yang telah membantu terselesaikannya program pengabdian ini.

\section{REFERENSI}

Cahyadi, W. (2006) 'Bahan Tambahan Pangan', Jakarta: Bumi Aksara

Direktorat Registrasi Pangan Olahan, (2018) 'Kenali Pewarna Makanan Yang Membahayakan', Badan POM RI. Jakarta.

Enie dalam Tatung, N. (2013) 'Analisis Zat Pewarna dan Pemanis Sintetis Serta Uji Mikrobiologis Pada Kue Cenil di Daerah Kota Yogyakarta', Skripsi, Universitas Atma Jaya Yogyakarta.

Julaeha, L., Nurhayati, A., dan Mahmudatussa'adah, A. (2016) 'Penerapan Pengetahuan Bahan Tambahan Pangan Pada Pemilihan Makanan Jajanan Mahasiswa Pendidikan Tata Boga UPI', Jurnal Media Pendidikan, Gizi dan Kuliner. 5(1), April.

Karunia, F. B. (2013) 'Kajian Penggunaan Zat Adiktif Makanan (Pemanis Dan Pewarna) Pada Kudapan Bahan Pangan Lokal Di Pasar Kota Semarang', Food Science and Culinary Education Journal, 2(2).

Peraturan Kepala BPOM RI no. 37. (2013) 'Batas Maksimum Penggunaan Bahan Tambahan Pangan Pewarna', Badan POM RI, Jakarta

Ristianingrum, C.T., Moelyaningrum, A. D. dan Pujiati, R. S. (2018) 'Higiene Sanitasi dan Zat Pewarna Rhodamin B pada Kue Cenil, Studi di Pasar Kecamatan Kota Kabupaten Jember', Journal of Health Science and Prevention, 2(2).

Rauf, R. (2013) 'Sanitasi dan HACCP', Graha Ilmu. Yogyakarta

Yulia, (2016) 'Higiene Sanitasi Makanan, Minuman, dan Sarana Sanitasi Terhadap Angka Kuman Peralatan Makan dan Minum Pada Kantin', Jurnal Vokasi Kesehatan, 2(1). 